Received: 2012.12.05

Accepted: 2013.06.05

Published: 2013.07.31

\title{
Effects of preoperative oral carbohydrate solution intake on thermoregulation
}

Authors' Contribution:

Study Design A

Data Collection B

Statistical Analysis C

Data Interpretation D

Manuscript Preparation E

Literature Search F

Funds Collection G
ABCDEF 1 Ayse B. Ozer

CDEF 1 Ismail Demirel

$B C D 2$ Burcin S. Kavak

BCD 1 Oguz Gurbuz

BCD 1 Serap Unlu

DEF 1 Mustafa K. Bayar

ADE 1 Ömer L. Erhan
1 Department of Anesthesiology and Reanimation, Firat University Medical School, Elazig, Turkey

2 Department of Obstetric and Gynecology, Firat University Medical School, Elazig, Turkey
Corresponding Author: Source of support:
Ayse B. Ozer, e-mail: abelinozer@gmail.com

Departmental sources

Background: We aimed to investigate the oral carbohydrate solution administered preoperatively on thermoregulation. Material/Methods: The study included 40 female patients under general anesthesia. Patients were randomly divided into 2 groups: Group CONT (stopped oral implementation $8 \mathrm{~h}$ before the operation) and Group CHO $(800 \mathrm{ml}$ oral carbohydrate fluid $8 \mathrm{~h}$ before the operation and $400 \mathrm{ml}$ oral carbohydrate fluid $2 \mathrm{~h}$ before the operation). Patients were monitored as standard and temperature probes were placed. Temperatures were recorded immediately before anesthetics induction, $5 \mathrm{~min}$ after the anesthetics induction, and in the post-anesthesia care unit (PACU) every $10 \mathrm{~min}$. Mean skin temperature (Tsk), mean body temperature (Tb), and vasoconstriction threshold were estimated.

Results: In general, we observed a decrease in tympanic temperature and Tb following anesthetic administration in groups, and increase in Tsk, and an increase in all 3 of these levels in the recovery unit. Tympanic temperature was significantly higher at 25, 55, 65, and 95 min after induction in Group CONT compared to Group CHO ( $p<0.05)$. Tsk was found to be lower in Group CONT compared to Group CHO in almost all periods. In PACU, it was found that the tympanic temperature was higher in Group CONT compared to Group $\mathrm{CHO}$ at $60 \mathrm{~min}$ $(p<0.05)$. Postoperative shivering score was found to be significantly higher in Group $C(p<0.01)$. Vasoconstriction threshold was higher in Group CONT than Group CHO.

Conclusions: Oral carbohydrate solution administered was established to have effects thought to be negative on tympanic temperature, vasoconstriction, and vasoconstriction threshold.

Key words: $\quad$ oral carbohydrate $\bullet$ thermoregulation $\bullet$ general anesthesia

Full-text PDF: http://www.medscimonit.com/download/index/idArt/883991

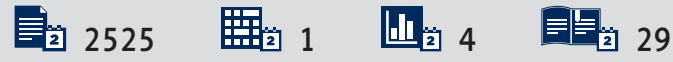




\section{Background}

Since human beings are homeothermic creatures, they need a steady central body temperature [1]. But, anesthetics are among the substances that alter the temperature regulation system and give patients a tendency to hypothermia. Certain methods have been developed to prevent hypothermia in intraoperative and postoperative periods. In addition to heating and humidifying the air being inhaled and heating intravenous fluid and transfused blood, methods of energy and heat generation formed by increasing the metabolism of the patient have been used in studies conducted in the last decade [1-5].

In the volunteers with intact thermoregulatory system, it has been demonstrated that enteral protein or amino acid infusions provoke thermogenesis [6,7] and hyperthermia [8]. The amino acid solution is also known to raise the trigger threshold in all the major autonomic thermoregulatory defense systems [9]. It has been demonstrated that amino acid and fructose solutions administered in preoperative and intraoperative periods generated temperature by increasing the metabolism and prevented hypothermia $[4,10]$. However, non-fructose carbohydrates have not been investigated for their effects on hypothermia due to anesthesia.

Recently it has become popular to administer solutions containing carbohydrates $2 \mathrm{~h}$ before the operation to decrease feeling of preoperative thirst, hunger, and anxiety, and insulin resistance [11]. It is not known if oral carbohydrates administered in the preoperative period have positive effects on thermoregulation, as do amino acid and fructose solutions. The aim of this study was to investigate the effects of preoperative administration of oral carbohydrate solution on heat regulation.

\section{Material and Methods}

This prospective, randomized, single-blind study (Australian New Zealand Clinical Trials Registry number: ACTRN12612000792820) was commenced following the approval of our Institutional Review Board and obtaining written consent of the patients. The study included 40 female patients who were to undergo myomectomy-hysterectomy under general anesthesia. The patients' ages ranged from 18 to 50 years, and they had I-II American Society of Anesthesiologists (ASA) physical status classification. Patients were chosen from among the cases scheduled to undergo surgery between 08:00 am and 13:00 pm. We excluded patients that had an inflammatory disease, diabetes mellitus, muscle diseases, hypo-hyperthyroidism, Parkinson disease, Raynaud phenomenon, menopause, with body mass index below 20 and above 30, used drugs affecting body temperature ( $\beta$-blocker, calcium channel blocker, clonidine, steroid, antiepileptic, NSAI, or benzodiazepine), and delayed gastric emptying (pregnancy, gastroesophageal reflux, opioid use), as were patients scheduled to undergo an operation that takes less than 60 min or more than $180 \mathrm{~min}$. Patients that had alterations in their hemodynamic parameters of more than $30 \%$, patients that required the use of vasopressor or vasodilator, and patients who needed blood transfusion were also excluded from the study.

Patients were randomly divided into 2 groups by using the opaque enveloped method. Group CONT (control group, $n=20$ ) included patients with oral intake stopped $8 \mathrm{~h}$ before the operation. Group $\mathrm{CHO}$ (preoperative carbohydrate group, $\mathrm{n}=20$ ) included patients that were administered oral carbohydrate fluid (Nutricia preop, Nutricia, Numil Gida Urunleri San. Tic. A.S. Istanbul, Turkey) prepared for the preoperative period as $800 \mathrm{ml}$ to be administered $8 \mathrm{~h}$ before the operation and as $400 \mathrm{ml} 2 \mathrm{~h}$ before the operation. Administration of anesthesia for patients that were not given premedication was conducted by the practitioner, who was not informed about which group the patient belonged to. In addition to electrocardiography (ECG), noninvasive blood pressure (NIBP), and peripheral oxygen saturation $\left(\mathrm{SpO}_{2}\right)$ monitoring by Draeger monitor (Draeger Cato Edition, Germany), patients' temperatures were monitored with temperature probes to measure tympanic membrane and peripheral temperature (chest, arm, $1 / 2$ inner midface of the forearm, ventral face of middle finger distal phalanx, thigh, and calf). Tympanic temperature was measured by a Genius 2 Tm Accusystem device (Genius 2 Tm Accusystem, Kendall, Mansfield, Massachusetts, USA), and peripheral temperature was measured by using a Draeger monitor (Draeger Cato Edition, Germany). Peripheral temperature measurements were conducted on the arm from which the fluid was not being given and a blood pressure cuff was not present. After preoxygenation, anesthesia was inducted by $5 \mathrm{mg} / \mathrm{kg}$ sodium thiopental, $0.1 \mathrm{mg} / \mathrm{kg}$ vecuronium, and $2 \mu \mathrm{g} / \mathrm{kg}$ fentanyl, and endotracheal intubation was carried out. Maintenance of anesthesia was obtained with desflurane in 5-6\% concentration with $50 \% \mathrm{O}_{2}-50 \% \mathrm{~N}_{2} \mathrm{O}$ with fresh gas flow of 4 liter/min. Respiration was mechanically maintained with $\mathrm{ETCO}_{2}$ adjusted as $30-40 \mathrm{mmHg}$. Throughout the surgery, fentanyl for analgesics and vecuronium for muscle relaxation were administered as additional doses when needed. Patients were covered with standard surgical drape during the operation and any heating method such as heated IV fluids, blankets, and hot air blow was not utilized. For humidification of inhaled air, an artificial humidifier was added between endotracheal tube and the $y$ connector of the respiration system. Operating room temperature was maintained at $20-23^{\circ} \mathrm{C}$. In recovery from anesthesia, when needed, $0.04 \mathrm{mg} / \mathrm{kg}$ neostigmine and $0.01 \mathrm{mg} / \mathrm{kg}$ atropine were administered intravenously to eliminate the residual muscle relaxation effect. Patients were extubated when laryngeal reflexes returned to normal and in the presence of sufficient spontaneous respiration. Patients that were covered 
Table 1. Patient's demographic data.

\begin{tabular}{|ccc|}
\hline & Group C & Group CH \\
\hline Age (year) & $42.10 \pm 6.93$ & $40.80 \pm 7.22$ \\
\hline ASA & $1.50 \pm 0.51$ & 1.4500 \\
\hline Operation duration $(\mathrm{min})$ & $110.00 \pm 31.07$ & $106.75 \pm 22.66$ \\
\hline Blood loss $(\mathrm{ml})$ & $219.23 \pm 133.13$ & $297.50 \pm 154.59$ \\
\hline Fluid volume $(\mathrm{ml})$ & $1836.84 \pm 537.70$ & $2194.73 \pm 719.93$ \\
\hline Room temperature $\left({ }^{\circ} \mathrm{C}\right)$ & $22.45 \pm 1.05$ & $23.26 \pm 1.62$ \\
\hline
\end{tabular}

with a single layer standard cloth in the PACU were monitored with ECG, NIBP, SpO2, tympanic membrane, and peripheral temperature measurements for an hour and $2 \mathrm{l} / \mathrm{min} \mathrm{O}_{2}$ was administered by face masks.

Heart rate (HR, beat/min), mean arterial pressure (MAP, $\mathrm{mmHg}$ ), central and peripheral temperatures, room temperature, and shivering score (0: no shivering, 1: presence of 1 or more of such findings as piloerection, peripheral vasoconstriction, and peripheral cyanosis without muscle movement, 2: presence of muscle activity observable in single muscle group, 3: presence of muscle activity in more than 1 muscle group, 4: presence of significant muscle activity observed in the whole body) were recorded immediately before anesthesia, in 5-min intervals after the induction of anesthesia, and in 10-min intervals in PACU [12]. Patients with 3 or more tremor score were administered 25 mg meperidine intravenously. In addition, mean skin temperature, mean body temperature, vasoconstriction time, and vasoconstriction threshold that triggers the central temperature were estimated with the help of recorded temperatures. Tsk was estimated with $[0.3($ Tchest + Tarm $)+0.2($ Tthigh + Tcalf)] formula [12]. Tb was calculated with [0.64 $\times$ Tcentral + $0.36 \times$ Tskin] formula [13]. Vasoconstriction was estimated with the [Tforearm- Tfingertip] formula of fingertip blood flow and the obtained value ' 0 ' demonstrates the vasoconstriction initiated and the value 4 shows severe vasoconstriction. Central temperature at the time of vasoconstriction formation shows the vasoconstriction threshold [14-16].

PACU complications (e.g., nausea, vomiting, and oxygen desaturation) were treated and recorded when they occurred. At the end of 1-h observation in PACU, patients with modified Aldrete recovery score of 9 and above were sent back to their clinics.

Statistical Package for Social Sciences (SPSS) 15.0 software was used for statistical evaluation. The obtained data were determined as mean \pm standard deviation. Implemented analyses were One-Way ANOVA and Mann Whitney $U$ test for comparisons between groups, and paired-samples t-test and Wilcoxon for in-group comparisons. Significance was set at $p<0.05$.

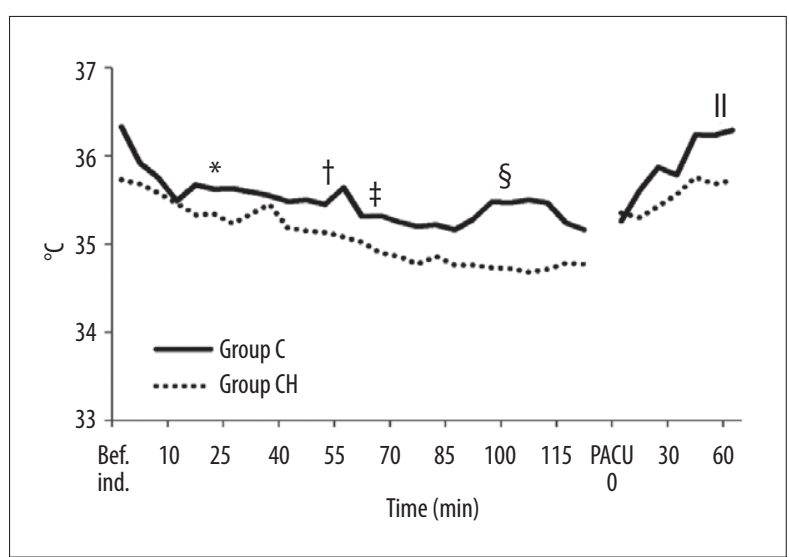

Figure 1. Groups' intraoperative and postoperative mean tympanic temperatures. * $\mathrm{p}<0.05$, when Group $\mathrm{CHO}$ was compared with Group CONT at the $25^{\text {th }}$ minute; $\dagger \mathrm{p}<0.05$, when Group $\mathrm{CHO}$ was compared with Group CONT at the $55^{\text {th }}$ minute; $\ddagger p<0.05$, when Group $\mathrm{CHO}$ was compared with Group CONT at the $65^{\text {th }}$ minute; $\S \mathrm{p}<0.05$, when Group CHO was compared with Group CONT at the $95^{\text {th }}$ minute; $\| \mathrm{p}<0.05$, when Group $\mathrm{CHO}$ was compared with Group CONT at the $60^{\text {th }}$ minute in the PACU.

\section{Results}

A significant difference was not observed between the patients, age, ASA class, duration of surgery, amount of bleeding, amount of fluid given, and room temperature (Table 1).

When compared the tympanic temperatures of patients between the groups, it was established that the temperatures were significantly higher in Group CONT compared to Group $\mathrm{CHO}$ before the induction and 25, 55, 65, and 95 min after the induction $(p<0.05)$. Tympanic temperature significantly decreased in both groups in subsequent time periods of time compared to the pre-induction period. The decreases commenced in Group CONT immediately after induction and in Group CHO 15 min after induction ( $<<0.05)$ (Figure 1).

When compared the Tsk between groups, it was established to be significantly lower in Group CONT compared to Group $\mathrm{CHO}$ in almost all periods (before the induction and 25, 30, 35, $40,50,55,60,65,70,75,80,85,95,100,105,110,115,120$, and $135 \mathrm{~min}$ after the induction) ( $\mathrm{p}<0.05)$. Tsk increased subsequent time periods in Group CONT compared to pre-induction values $(\mathrm{p}<0.05)$. In Group $\mathrm{CHO}$, it decreased significantly at the 5th minute after induction, and increased after the $15^{\text {th }}$ minute $(p<0.05)$ (Figure 2).

When comparing the Tb between groups, a significant difference was not established. In the in-group comparison of Tb, $\mathrm{Tb}$ was decreased subsequent time periods compared to preinduction values in both groups $(p<0.05)$ (Figure 3 ). 


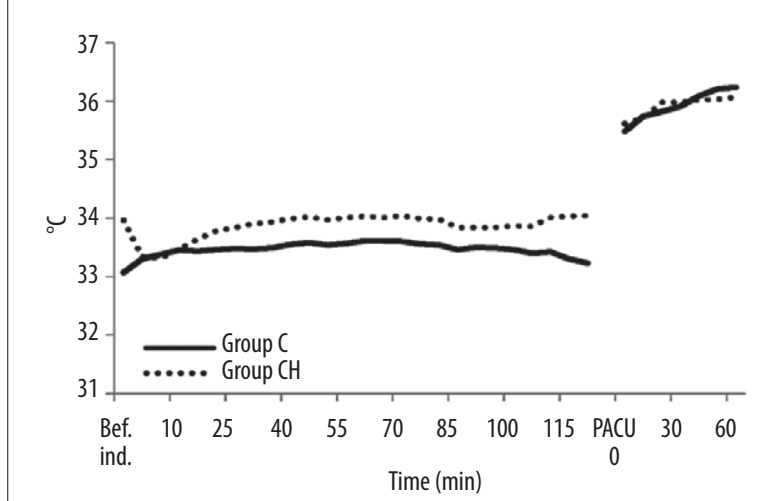

Figure 2. Groups' intraoperative and postoperative mean skin temperatures. $\mathrm{p}<0.05$ : when Group $\mathrm{CHO}$ was compared with Group CONT at before induction and 25, 30, 35, $40,50,55,60,65,70,75,80,85,95,100,105,110$, 115,120 and 135 minutes after the induction.

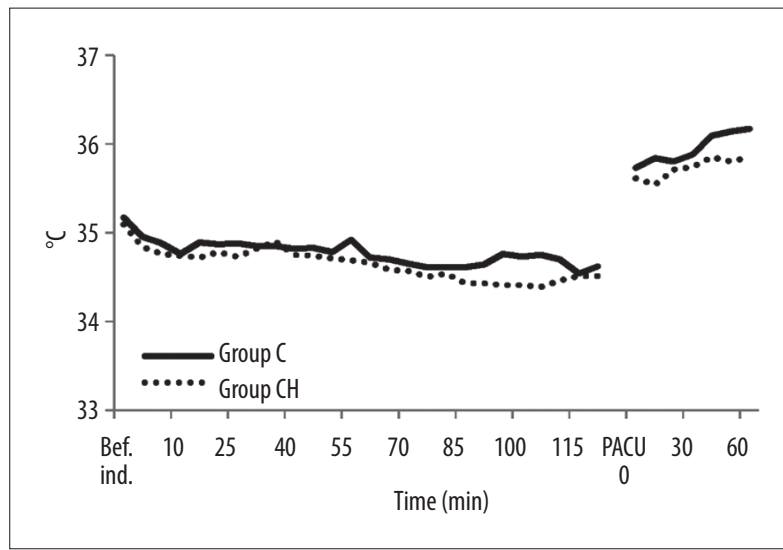

Figure 3. Groups' intraoperative and postoperative mean body temperatures.

When evaluating the temperature in PACU, tympanic temperature was higher in Group CONT at the 60th minute compared to Group $\mathrm{CHO}(\mathrm{p}<0.05)$. In the in-group comparison, tympanic temperature, Tsk, and Tb of both groups gradually increased from the time the patients arrived at the recovery room $(p<0.05)$.

Postoperative shivering score was higher in Group CONT compared to Group $\mathrm{CHO}(\mathrm{p}<0.01)$ (Figure 4).

The forearm-finger temperature gradient before the anesthesia induction was $1.69 \pm 2.23^{\circ} \mathrm{C}$ in Group CONT and $0.78 \pm 2.15^{\circ} \mathrm{C}$ in Group $\mathrm{CHO}(\mathrm{p}<0.05)$. Vasoconstriction occurred at the $50^{\text {th }}$ minute in Group CONT and the mean tympanic temperature during the occurrence of vasoconstriction, or the vasoconstriction threshold, was $35.45 \pm 0.72^{\circ} \mathrm{C}$, it occurred at the $75^{\text {th }}$ minute in Group $\mathrm{CHO}$ and the mean tympanic temperature during the occurrence of vasoconstriction, or the vasoconstriction threshold, was $34.77 \pm 0.53^{\circ} \mathrm{C}$. Vasoconstriction after taking the

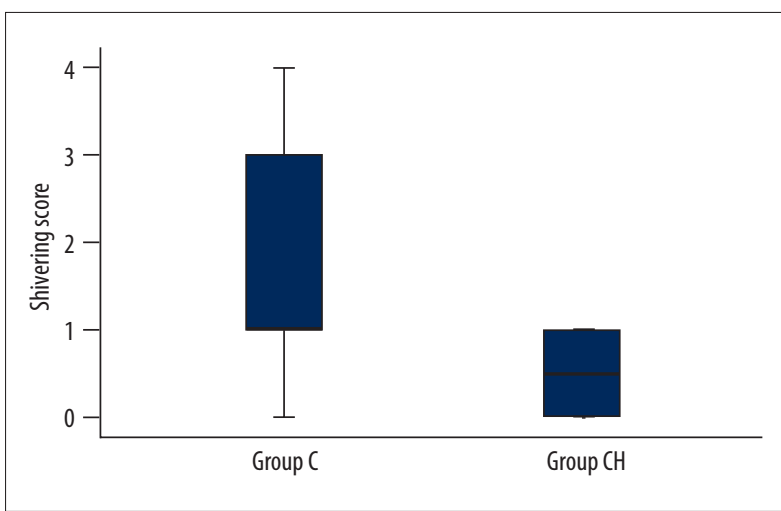

Figure 4. Groups' postoperative shivering scores.

patients into the recovery room after 10,20 , and $30 \mathrm{~min}$, vasoconstriction was more significant in Group CONT compared to Group $\mathrm{CHO}(\mathrm{p}<0.05)$.

\section{Discussion}

In routine anesthesia practices, oral intake is stopped $8 \mathrm{~h}$ before the elective surgery to decrease the aspiration risk in adults [11]. However, in recent years it was demonstrated that the administration of fluids containing water or carbohydrate 2 hours before the operation instead of preoperative 8-hour fasting had positive effects [17]. In this study, we investigated the effects of preoperative carbohydrate solutions, which are more preferred in routine practice, on disordered temperature regulation, which is a significant issue in anesthesia applications.

In our study, the expected increase in tympanic temperature in patients that were administered carbohydrate solution in the preoperative period did not occur, and a significant decrease was observed in the carbohydrate group compared to the control group. In patients given carbohydrate solution, mean skin temperature increased in a delayed manner and more significantly, and a significant change was not observed in mean body temperature. In the control group, vasoconstriction was more significant, occurred earlier, and the threshold was higher.

In our study, we believe there are 6 reasons why our results do not match those of previous studies, especially in terms of tympanic temperature and vasoconstriction threshold. Firstly, hypothermia caused by anesthesia was one of application area of diet induced thermogenesis. Here, the most frequently used nutrients are amino acids. It was noted that amino acid solution administered $1-2 \mathrm{~h}$ before general anesthesia induction and at the first hour of the maintenance of anesthesia as $240 \mathrm{kj} / \mathrm{h}$ has been suggested to increase heat accumulation and prevent hypothermia by delaying heat generation stimulation and to increase vasoconstriction threshold, and that postoperative shivering were not observed [18-21]. In addition, when amino acid 
solution was administered to patients under spinal anesthesia, central temperature increased before performing spinal anesthesia and the decrease in central temperature reduced after performing it $[22,23]$. In a study in which lower doses of amino acid solution was administered, the effects of amino acid solution given as $100 \mathrm{kj} /$ hour in the intraoperative period on central temperature in patients that were administered isoflurane anesthesia were not observed; however, positive effects were established on the central temperature in patients that were administered propofol anesthesia [4]. Furthermore, fructose is superior to glucose (although both are hexose monosaccharide) because: a) fructose is mainly metabolized in the liver, b) fructokinase is more active than glucokinase and hexokinase, and c) fructose is a better substrate for hepatic gluconeogenesis because it causes a smaller increase in insulin concentration. The solution used in our study did not contain a nutrient that included high energy like amino acid or fructose.

Secondly, thermogenesis induced by diet is either obligatory or facultative. Obligatory thermogenesis is the energy needed for digestion and absorption of food and its metabolisms. Facultative thermogenesis is the energy spent in excess of obligatory thermogenesis [24]. Type and route of administration of food and sympathoadrenal system activation are among the factors that determine thermogenesis induced by diet $[10,18,19,25,26]$. Proteins are the main nutrients that product energy carbohydrates, followed by fats $[10,18,19]$. Carbohydrates that occupy the second place in terms of energy were also used for this purpose. Mizobe et al. [10] administered a fructose infusion $(0.5 \mathrm{~g} / \mathrm{kg} / \mathrm{h}) 3 \mathrm{~h}$ before anesthesia induction and maintained it until $1 \mathrm{~h}$ after the anesthesia induction. In patients that were administered fructose, central temperature was observed to significantly increase beginning from the $20^{\text {th }}$ minute of anesthesia induction until the $180^{\text {th }}$ minute. The vasoconstriction threshold was also found to be significantly higher in patients that were given fructose compared to patients that did not receive fructose. Regarding the effects of glucose (i.e., carbohydrates) on thermogenesis, central temperature decreased even though a $20 \%$ increase was found in temperature generation after $500 \mathrm{ml}$ intravenous infusion of $20 \%$ glucose, and skin temperature increased [27]. Therefore, we believe that the solution administered at the established time and dose could cause obligatory thermogenesis but it was not able to generate energy sufficient for facultative thermogenesis. This is why we did not establish an increase in tympanic temperature and vasoconstriction threshold.

\section{References:}

1. Sessler D: Temperature monitoring. In: Miller RD (ed.), Miller's Anesthesia. $7^{\text {th }}$ ed. Philadelphia: Elsiever Churchill Livingstone, 2010; 1367-89

2. Sessler DI: Perioperative heat balance. Anesthesiology, 2000; 92: 578-96

3. Steven MF, Kha MT, Lee AF: Clinical importance of body temperature in the surgical patient. J Therm Biol, 2000; 25: 151-55
Thirdly, carbohydrate was given orally in our study. When nutrients are administered intravenously, its effects on thermogenesis are more significant compared to oral intake [25].

Fourthly, thermogenesis occurs after the nutrient is received and then it is terminated. As in the case of amino acid and fructose studies, in studies in which facultative thermogenesis occurred, solutions were began preoperatively and continued to be given during anesthesia for a few hours. In our study, the solution was administered 2 and 8 hours before the operation, in accordance with suggestions, due to aspiration risk.

Fifthly, it is also known that the sympathoadrenal system modulates the thermal effects of nutrients. It was shown that nutrients with carbohydrate contents lower than $20 \%$ do not change noradrenaline concentration [28]. The carbohydrate content of the solution used in our study was $12.6 \%$. Because the solution we used did not contain carbohydrates sufficient for sympathetic system activation, it was believed that it was unable to generate thermoregulatory response.

Sixthly, unlike other studies, a placebo group with fluids containing no calories was not created in our study. If there was a placebo group, perhaps more temperature decrease would have been observed in the said group since it was shown in the literature that central temperature measured $150 \mathrm{~min}$ utes after a drink that does not contain energy, such as lemon squeeze, decreased significantly [29].

In line with studies that demonstrated a decrease in shivering, or even elimination of it, in patients who were administered amino acid solution $[18,19,21,23]$, we found that shivering decreased in patients who were given carbohydrates.

\section{Conclusions}

As a result of our study, it was established that oral carbohydrate solution administered preoperatively did not provide the expected increase in tympanic temperature, vasoconstriction, and vasoconstriction threshold; on the contrary, it had decreasing effects, but it significantly decreased postoperative shivering. Therefore, we believe that the combined use of an additional temperature-preserving method would be beneficial in patients given preoperative carbohydrate.

4. Şahin A, Aypar Ü: Effect of amino acid solutions on intraoperative hypothermia and postoperative shivering. Acta Anaesthesiol Scand, 2002; 46: 64-67 
5. Petrofsky JS, Berk L, Alshammari F et al: The interrelationship between air temperature and humidity as applied locally to the skin: the resultant response on skin temperature and blood flow with age differences. Med Sci Monit, 2012; 18(4): CR201-8

6. Brundin T,Wahren J: Influence of mixed meal on splanchnic and interscapularenergy expenditure in humans. Am J Physiol, 1991; 260: E232-37

7. Sellden E, Branstorm R, Brundin T: Augmented thermic effect of amino acids under general anesthesia occurs predominantly in extrasplanchnic tissues. Clin Sci, 1996; 91: 431-39

8. Kasai T, Nakajima Y,Matsukawa T et al: Effect of preoperative amino acid infusion on thermoregulatory response during spinal anesthesia. Br J Anaesth, 2003; 90: 58-61

9. Brundin T,Wahren J: Effects of i.v.amino acids on human splanchnic and whole body oxygen consumption, blood flow, and blood temperatures. Am J Physiol, 1994; 266: E396-402

10. Mizobe T, Nakajima Y, Ueno H, Sessler DI: Fructose Administration Increases intraoperative Core Temperature by Augmenting Both Metabolic Rate and the Vasoconstriction Threshold. Anesthesiology, 2006; 104: 1124-30

11. Smith I, Kranke P, Murat I et al: Perioperative fasting in adults and children: guidelines from the European Society of Anaesthesiology. Eur J Anaesthesiol, 2011; 28: 556-69

12. Shanks CA: Mean skin temperature during anaesthesia: an assessment of formulae in the supine surgical patient. Br J Anaesth, 1975; 47: 871-76

13. Ramanathan NL: A new weighting system for mean surface temperature of the human body. J Appl Physiol, 1964; 19: 531-33

14. Rubinstein EH, Sessler DI: Skin-surface temperature gradients correlate with fingertip blood flow in humans. Anesthesiology, 1990; 73: 541-45

15. Sessler DI: Skin-temperature gradients are a validated measure of fingertip perfusion. Eur J Appl Physiol, 2003; 89: 401-2

16. House JR, Tipton MJ: Using skin temperature gradient or skin heat flux measurements to determine thresholds of vasoconstriction and vasodilatation. Eur J Appl Physiol, 2002; 88: 141-45
17. de Aguilar-Nascimento JE, Dock-Nascimento DB: Reducing preoperative fasting time: A trend based on evidence. World J Gastrointest Surg, 2010 2: $57-60$

18. Sellden E, Branstrom R, Brundin T: Preoperative infusion of amino acids prevents postoperative hypothermia. Br J Anaesth, 1996; 76: 227-34

19. Sellden E, Lindahl SGE: Postoperative nitrogen excretion after amino acidinduced thermogenesis under anesthesia. Anesth Analg, 1998; 87: 641-46

20. Yamaoka I, Doi M, Nakayama $M$ et al: Intravenous administration of amino acids during anesthesia stimulates muscle protein synthesis and heat accumulation in the body. Am J Physiol Endocrinol Metab, 2006; 290: E882-88

21. Nakajima Y, Takamata A, Matsukawa T et al: Effect of amino acid infusion on central thermoregulatory control in humans. Anesthesiology, 2004; 100: 634-39

22. Widman J, Hammarqvist F, Sellden E: Amino acid infusion induces thermogenesis and reduces blood loss during hip arthroplasty under spinal anesthesia. Anesth Analg, 2002; 95: 1757-62

23. Kasai T, Nakajima Y, Matsukawa T et al: Effect of preoperative amino acid infusion on thermoregulatory response during spinal anaesthesia. $\mathrm{Br}$ Anaesth, 2003: 90: 58-61

24. Coward-McKenzei D, Johnson RK: Energy requirement methodology. In Coulston AM, Boushey CJ, editors. Nutrition in the prevention and treat ment of disease. $2^{\text {nd }}$ ed. California: Elsevier academic press, 2008; 75-88

25. Acheson KJ: Influence of autonomic nervous system on nutrient-induced thermogenesis in humans. Nutrition, 1993; 9: 373-80

26. Tappy L: Thermic effect of food and sympathetic nervous system activity in humans. Reprod Nutr Dev, 1996; 36: 391-97

27. Green JH, Macdonald IA: The influence of intravenous glucose on body temperature. Q J Exp Physiol, 1981; 66: 465-73

28. van Baak MA: Meal-induced activation of the sympathetic nervous system and its cardiovascular and thermogenic effects in man. Physiol Behav, 2008; 94: 178-86

29. Pittet $P$, Chappuis $P$, Acheson $K$ et al: Thermic effect of glucose in obese subjects studied by direct and indirect calorimetry. Br J Nutr, 1976; 35: 281-92 